\title{
DINÂMICA TEMPORAL NA LAGOA DO CAMPELO, REGIÃO NORTE DO ESTADO DO RIO DE JANEIRO, BASEADA EM ESTUDOS PALINOLÓGICOS
}

\author{
CYNTHIA FERNANDES PINTO DA LUZ \\ Laboratório de Palinologia, Departamento. Botânica, UFRJ, Rio de Janeiro. Seção de Dicotiledôneas, \\ Instituto de Botânica, Secretaria do Meio Ambiente, São Paulo, Brasil.cyluz@yahoo.com.br

\section{ORTRUD MONIKA BARTH} \\ Laboratório de Palinologia, Departamento de Botânica, UFRJ, Rio de Janeiro. \\ Departamento de Virologia, Instituto Oswaldo Cruz, FIOCRUZ, Rio de Janeiro, Brasil. barth@ioc.fiocruz.br

\section{CLEVERSON GUIZAN SILVA} \\ Laboratório de Geologia Marinha, Instituto de Geologia, UFF, Rio de Janeiro, Brasil. cleverson@igeo.uff.br

\begin{abstract}
RESUMO - Este trabalho visa analisar os processos temporais que influenciaram a sedimentação de palinomorfos em depósitos da lagoa do Campelo (município de Campos dos Goitacazes, Estado do Rio de Janeiro). Formada no Holoceno, durante a colmatação de uma vasta paleolaguna, a lagoa conectava-se ao rio Paraíba do Sul pelo canal da Cataia, que a alimentava de água durante as cheias. Obras de drenagem realizadas em 1950 mudaram a configuração geomorfológica original e geraram dois novos canais, um ligando a lagoa ao rio, outro ao mar, que, por vários motivos, acabaram transformando em negativo o balanço hídrico da lagoa. As análises das amostras refletiram uma vegetação hidrófita bem representada em cerca de 2.790 anos A.P. $\left({ }^{14} \mathrm{C}\right.$ convencional $)$, com baixa riqueza de tipos polínicos e altas concentrações da alga Pseudoschizaea, caracterizando o desenvolvimento de um ambiente encharcado, com lâmina d'água muito reduzida. Este período correspondeu ao abaixamento do nível do mar iniciado em 2.800 anos A.P., que acarretou a progradação da desembocadura do rio Paraíba do Sul. Com a elevação do nível do mar a partir de 2.700 anos A.P., processos erosivos passaram a atuar na desembocadura do rio Paraíba e iniciou-se o progressivo represamento das águas na planície. Próximo ao período de pico eustático positivo, em cerca de 2.500 anos A.P. (idade interpolada), a deposição polínica no local foi facilitada pela subida do nível de base da lagoa. Já em cerca de 2.320 anos A.P. $\left({ }^{14} \mathrm{C}\right.$ convencional), a taxa de acumulação total dos palinomorfos foi muito alta, principalmente pelo aumento dos tipos herbáceos e de hidrófitas. O registro
\end{abstract} \\ sedimentar após 2.320 anos A.P. foi praticamente nulo no local da perfuração.
}

Palavras-chave: Palinologia, lagoa do Campelo, Rio de Janeiro, Holoceno Superior.

ABSTRACT - TEMPORAL DYNAMICS IN LAGOA DO CAMPELO, NORTHERN REGION OF THE STATE OF RIO DE JANEIRO, BASED ON PALYNOLOGYCAL STUDIES. This study aims to analyze the temporal processes that influenced the palynomorph sedimentation in the Campelo Lake (Campos dos Goitacazes municipality, Rio de Janeiro State, Brazil). Formed during the Holocene by the isolation of a large paleolagoon, this lake was connected in the past to the Paraíba do Sul River by Cataia's channel which fed it with waters during the inundations. Drainage modifications in the Campos municipality realized in 1950 changed the geomorphological configuration of the Campelo Lake and two new channels were constructed, connecting the lake to the river and to the sea, respectively, which transformed in negative the hydrological balancing of the lake by several reasons. The palynological analysis reflected around 2,790 years B.P. $\left({ }^{14} \mathrm{C}\right.$ conventional age $)$ hydrophytic vegetation well represented, with low number of pollen types and a high Pseudoschizaea deposition characterizing the development of a wet environment with lower water level. That period corresponded to the descent of the sea level initiated in 2,800 years B.P. which carried the progradation of the outlet of the Paraíba do Sul River. With the elevation of sea level starting from 2,700 years B.P., that causes the erosion in the outlet of the river Paraíba, occurred a progressive damming of waters in the low plain. Near the period of a maximum sea level around 2.500 years B.P. (interpolated age) pollen deposition in the local was facilitated by the rise of water level in the lake. About 2,320 years B.P. $\left({ }^{14} \mathrm{C}\right.$ conventional age) the Rate of Total Accumulation of palinomorphs was very high, mostly by increase of the herbaceous types and of the hydrophytes. In the location of the core the sedimentation behind 2,320 years B.P. was practically null.

Key words: Palynology, Campelo Lake, Rio de Janeiro, Late Holocene. 


\section{INTRODUÇÃO}

A lagoa do Campelo, localizada na margem esquerda da foz do rio Paraíba do Sul, município de Campos dos Goitacazes (Norte Fluminense), surgiu como fruto do isolamento de uma bacia lagunar, no Holoceno superior, associado à formação de cordões de dunas (Martin et al., 1984, 1993). Esta região vem sendo submetida a processos de erosão e deposição sucessivos em face das próprias transgressões e regressões marinhas e da grande dinâmica natural provocada pelo volume de sedimentos trazidos para a linha de costa, inclusive pelo rio Paraíba do Sul. Recentemente, esses processos vêm se intensificando por causa da ocupação humana desordenada tanto da planície quanto das terras a montante (Bidegain, 2002).

Textos históricos afirmam que o Norte Fluminense foi mais pródigo, no passado, em termos de lagoas e brejos. Os prejuízos ambientais decorrentes das atividades dos grupos indígenas da grande nação Macro-jê, que ocupavam a região de Campos, parece terem sido menores se comparados aos provocados pelo colonizador europeu. Estudos antracológicos em sítios arqueológicos, desenvolvidos em sambaquis por Scheel-Ybert (2000) em Cabo Frio, Saquarema e Arraial do Cabo (municípios localizados ao sul de Campos dos Goitacazes) sugerem que as populações pré-históricas mantiveram nessa costa um sistema sociocultural estável por mais de seis mil anos, ocupando os lugares próximos ao mar e integrando diversos ecossistemas como lagoas, restingas, mangues e florestas, utilizando madeira morta do entorno dos sítios como lenha. Ao contrário, para os europeus colonizadores, a natureza da região Norte Fluminense pareceu um paraíso íntegro, habitado por povos em estado précivilizacional, e que precisava ser domesticada e profundamente explorada para ser integrada à civilização. $\mathrm{O}$ maior problema para eles dizia respeito à existência de lagoas, brejos e os cursos baixos dos rios, aliados ao clima tropical, desconhecido na Europa (Soffiati Neto, 1997; Bidegain, 2002). Um grande marco de pressão ambiental para a região se deu a partir de 1950 com a realização de obras hidráulicas pelo Departamento Nacional de Obras de Saneamento (DNOS), que buscou solucionar os problemas das inundações baseando-se nas premissas de que as lagoas eram "desastres ecológicos, biologicamente desequilibradas e inúteis". Como conseqüências dessas obras, vêm ocorrendo: o dessecamento da superfície das lagoas, a salinização dos solos, o rebaixamento do lençol freático, o aumento da velocidade do escoamento e aprofundamento do leito dos rios, a ressuspensão de sedimentos finos previamente depositados nestes leitos, o aumento da turbidez das águas, a desfiguração das calhas, o desmonte de barranca solapando as margens e a criação de enseadas laterais, o que afeta a flora e a fauna pela destruição de nichos ecológicos e de hábitats (Soffiati Neto, 1985; FEEMA, 1993; Bidegain, 2002). A lagoa do Campelo é um dos casos mais urgentes de atenção, já que seu nível de água vem baixando drasticamente nos últimos anos.

O presente trabalho tem como objetivo investigar, por meio da análise palinológica de um testemunho de sondagem, as variações do nível de água da lagoa do Campelo, as respostas da vegetação local às mudanças ocorridas e os processos que vêm influenciando a deposição de grãos de pólen, esporos de Pteridophyta, esporos de Bryophyta e algas durante o Holoceno Superior.

\section{ÁREA DE ESTUDO}

A lagoa do Campelo apresenta tendência à forma alongada na direção norte-sul e se localiza a $41^{\circ} 11^{\prime} \mathrm{W}$ e a $21^{\circ} 39^{\prime} 01^{\prime \prime S}$, nas coordenadas quilométricas 7604/274. Dista cerca de 17 $\mathrm{km}$ da linha da costa para oeste e está posicionada numa altitude de cerca de $8 \mathrm{~m}$. Sua bacia de drenagem é mal definida e ocupa uma área de $9,8 \mathrm{~km}^{2}$. Com topografia de fundo praticamente plano, apresenta profundidade máxima de cerca de 1,7 m (Figura 1). A lagoa do Campelo não apresenta estratificação térmica (Esteves et al., 1984; Reid \& Esteves, 1984). Está situada no curso inferior do rio Paraíba do Sul. Originalmente sem afluentes e efluentes principais, a lagoa do Campelo recebia o aporte de água do rio Paraíba do Sul, durante as cheias, através do canal da Cataia. Também era abastecida pela água proveniente de vários brejos de seu redor, especialmente do brejo do Campelo que recebe águas da Vala do Norte (próxima ao Sistema Barreiras). Quando realizadas as obras do DNOS, foi destinada para a lagoa do Campelo a construção de canais e diques que serviriam como pretexto de torná-la estabilizadora de águas pela margem esquerda do rio Paraíba do Sul, para absorver o excedente hídrico através de um canal artificial (canal do Vigário) e com escoamento para o mar por um outro canal artificial (canal Antônio Rezende).

O previsto era que durante a estiagem, os déficits de água seriam contrabalançados com o fornecimento de água pelo rio Paraíba do Sul. Para evitar a conseqüente inundação dos pastos, o DNOS construiu um dique-estrada na margem esquerda e manteve a comunicação do canal da Cataia com o rio Paraíba através de três tubos por sobre a estrada, onde comportas automáticas permitiriam a circulação das águas no sentido lagoa-rio, impedindo o fluxo no sentido inverso. Quando o canal do Vigário foi concluído, uma usina o obstruiu a fim de aproveitá-lo para irrigação. O extravasador construído pelo DNOS na confluência da lagoa com o canal Antônio Rezende acabou ficando em cota inferior à prometida. Tudo isso transformou em negativo o balanço hídrico da lagoa do Campelo, tanto por escoar mais água do que recebe, quanto devido ao dessecamento dos brejos circundantes que a abasteciam. A pouca profundidade favoreceu a proliferação de plantas hidrófitas e a eutrofização (Soffiati Neto, 1985; FEEMA, 1993; Bidegain, 2002).

O clima na região é nitidamente estacional, com inverno seco e verão úmido (Moreno et al., 2003). A deficiência hídrica é grande constituindo-se no dobro da precipitação. A temperatura média anual caracteriza-se por valores elevados, entre 19 e $23^{\circ} \mathrm{C}$ (FEEMA, 1993). A vegetação original do entorno da lagoa era a Floresta Estacional Semidecidual, Floresta da Restinga e a vegetação herbácea das áreas encharcadas (RADAMBRASIL, 1983). Atualmente, Typha sp. coloniza toda a orla da lagoa. Em trabalhos de campo 


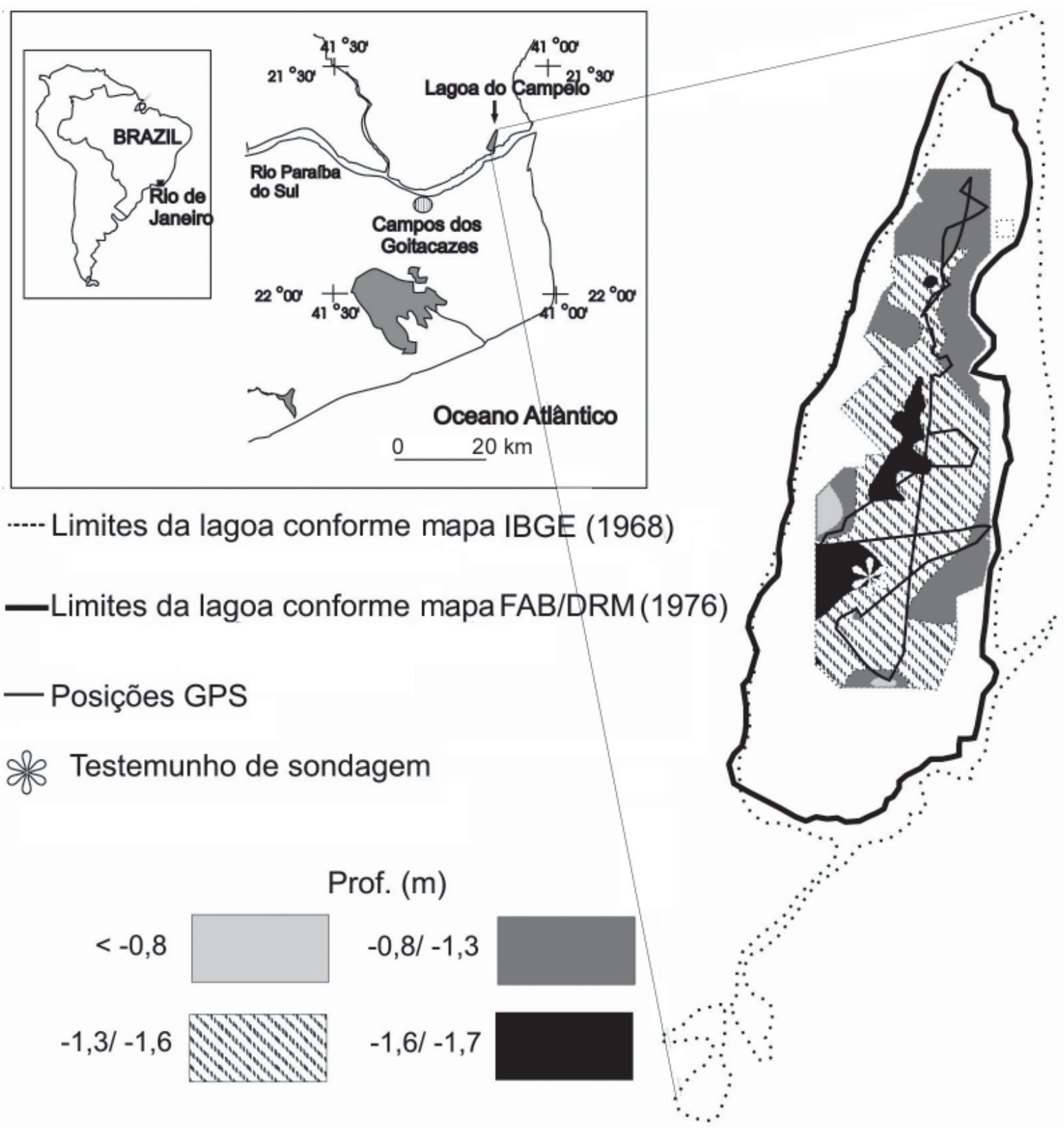

Figura 1. Localização do testemunho de sondagem Campelo 2001 e batimetria da lagoa do Campelo.

Figure 1. Location of the core Campelo 2001 and bathymetry of Campelo Lake.

realizados em junho de 1999 e julho de 2001, pode ser observado que o nível de água apresentou uma diminuição acentuada e que houve ampliação da área de colonização de Typha sp, de monocotiledôneas aquáticas emersas da família Hydrocharitaceae (Egeria densa/Anacharis densa), assim como de um gênero de Bryophyta aquática.

\section{MATERIAIS E MÉTODOS}

O testemunho de sondagem denominado Campelo 2001 alcançou 2,05 $\mathrm{m}$ de comprimento e foi retirado por percussão com um tubo de alumínio de $7,5 \mathrm{~cm}$ de diâmetro da porção central/sudoeste $\left(21^{\circ} 40^{\prime} 03^{\prime \prime} \mathrm{S}, 41^{\circ} 11^{\prime} 40^{\prime \prime} \mathrm{W}\right)$ da lagoa, em julho de 2001 num dos locais mais profundos e centrais da lagoa (Figura 1). Sedimentos com conteúdo orgânico foram separados para a datação radiocarbônica e enviados para o laboratório Beta Analytic (Flórida, Estados Unidos da América). Para a análise palinológica das amostras do testemunho de sondagem foram separados $2 \mathrm{~g}$ (peso úmido) de seis níveis estratigráficos, escolhidos previamente de acordo com as mudanças litológicas. Os níveis estratigráficos selecionados foram: $0,2 \mathrm{~m} ; 0,98 \mathrm{~m} ; 1,93 \mathrm{~m} ; 2,00 \mathrm{~m} ; 2,03 \mathrm{~m} ; 2,04 \mathrm{~m}$.

A metodologia adotada para o tratamento físico-químico dos sedimentos do testemunho de sondagem foi baseada em Ybert et al. (1992). Procurou-se contar uma média de 300 grãos de pólen por amostra, no entanto, as somas polínicas foram 
menores naquelas menos ricas. Da soma polínica excluiu-se os esporos de Pteridophyta e Bryophyta, algas e grãos de pólen de hidrófitas (Typhaceae, Cyperaceae, Onagraceae, Scrophulariaceae, Utricullaria, Eicchornia, Nymphaceae e Sagittaria) por fazerem parte do próprio ambiente lacustre e que poderiam estar super-representados em nível local nos sedimentos do testemunho de sondagem (Jacobson \& Bradshaw, 1981). A obtenção dos valores absolutos dos palinomorfos foi realizada pelo método de Stockmar (1971). A interpolação linear das idades no testemunho de sondagem foi realizada de acordo com os cálculos das taxas de sedimentação para os intervalos. O tratamento estatístico dos dados foi realizado através do software Tilia e plotados em diagramas pelo Tiliagraph (Grimm, 1987).

A caracterização dos tipos de vegetação ocorrentes na região se baseou em Veloso et al. (1991) e em levantamentos florísticos realizados pelo RADAMBRASIL (1983) (Folha SF: 23/24 RJ/Vitória). O enquadramento dos tipos polínicos com base no hábito das plantas se deu de acordo com os estudos florísticos realizados por Carauta et al. (1978), Araújo \& Henriques (1984), Carauta \& Rocha (1988), Carauta et al. (1992), Guedes-Bruni et al. (1997), Pessoa et al. (1997), Lima et al. (1998), Moreno et al. (1998), Assumpção \& Nascimento (2000), Kurtz \& Araújo (2000), Silva \& Nascimento (2001) e Moreno et al. (2003).

A categorização adotada para o hábito arbóreo incluiu as plantas lenhosas, de altura superior a $5 \mathrm{~m}$, com tronco bem marcado e sem ramos na parte inferior. Para o arbustivo correspondeu àquelas plantas lenhosas, de altura inferior a 5 $\mathrm{m}$, revestidas de ramos desde a base. O herbáceo incluiu as plantas com caule pouco alongado, de consistência herbácea ou sub-herbácea, anuais ou vivazes, podendo ainda ter o caule extremamente reduzido (acaules). Na categoria lianas (ou cipós) foram consideradas as plantas de caule flexível e lenhoso que se mantêm agarrando-se a suportes (Angely, 1959). A categoria de "hábito variável" incluiu aqueles gêneros de plantas que podem apresentar várias formas de vida. As categorias "arbóreo/arbustivo" e "herbáceo/ arbustivo" incluem os gêneros de plantas que podem se apresentar em ambas formas de vida. Hidrófita designa macrófitas associadas aos ecossistemas aquáticos cujas partes fotossintetizantes ativas estão permanentemente ou, por diversos meses e em todos os anos, total ou parcialmente submersas em água doce, ou ainda aquelas flutuantes (Bove et al., 2003).

Os danos causados aos palinomorfos foram definidos segundo a classificação de Campbell (1991) em dano mecânico (indicativo de transporte), corrosão (indicativo de ataque microbiano) e degradação (indicativo de oxidação).

\section{RESULTADOS}

A litologia dos sedimentos consistiu em turfa (205 a 204 cm, 93 a $13 \mathrm{~cm}$ ), argila (203 a $202 \mathrm{~cm}, 199$ a $171 \mathrm{~cm}, 161$ a 124 $\mathrm{cm}, 105 \mathrm{a} 104 \mathrm{~cm})$, argila fluida $(13 \mathrm{a} 0 \mathrm{~cm})$, areia fina a muito fina (201 a $200 \mathrm{~cm}, 172$ a $162 \mathrm{~cm}, 123$ a $121 \mathrm{~cm}, 95$ a $94 \mathrm{~cm})$, fragmentos vegetais centimétricos $(193-179 \mathrm{~cm}, 120-118 \mathrm{~cm}$,
$63-73 \mathrm{~cm})$ e lama rica em fragmentos vegetais $(119-96 \mathrm{~cm})$ (Figura 2). Datações radiocarbônicas convencionais em turfa indicaram que a sedimentação na lagoa do Campelo atingiu cerca de $0,385 \mathrm{~cm} /$ ano entre $2.320 \pm 80$ anos A. P. em $16-23 \mathrm{~cm}$ (número de registro Beta 157947) e 2.790 40 anos A. P em 204-205 cm (número de registro Beta 157950) (Figura 2). Nas seis amostras analisadas do testemunho (níveis $0,2 \mathrm{~m} ; 0,98$ $\mathrm{m} ; 1,93 \mathrm{~m} ; 2,00 \mathrm{~m} ; 2,03 \mathrm{~m} ; 2,04 \mathrm{~m}$ ) foram identificados 42 tipos polínicos (Apêndice 1).

A sedimentação no testemunho de sondagem da lagoa do Campelo abrangeu cerca de 500 anos e refletiu mudanças na vegetação e nas condições sedimentológicas. Na camada de turfa da base do testemunho de sondagem, datada em cerca de 2.790 anos A. P., a amostra analisada mostrou uma grande riqueza e alta deposição em palinomorfos, com destaque para os herbáceos e as hidrófitas (Figura 3). A concentração total dos palinomorfos foi alta, atingindo cerca de 250.000 palinomorfos/grama de sedimento (Figuras 2 e 3). Nessa amostra foram observados esporos de Selaginella, Pteridophyta e Bryophyta, tipos polínicos relacionados às hidrófitas (Cabomba, Polygonum, Sagittaria, Scrophulariaceae, Typhaceae e Cyperaceae), aos herbáceos (Araceae, Borreria e Poaceae), aos arbóreos/arbustivos (Alchornea e Cecropia), arbustivos (Loranthaceae e Piper), aos de hábito variável (Asteraceae, Euphorbiaceae, Melastomataceae/Combretaceae, Moraceae, Ochnaceae, Rhamnaceae e Tiliaceae), assim como altas concentrações de Pseudoschizae (Figura 3). Nessa amostra, foi alto o percentual de palinomorfos que apresentaram a exina degradada e corroída (cerca de $26 \%$ ).

Com a posterior introdução de argilas (em $203 \mathrm{~cm}$ ), a riqueza em tipos polínicos e a concentração total dos palinomorfos diminuíram muito (cerca de 50.000 palinomorfos/grama de sedimento) (Figuras 2 e 3). Somente foram observados na amostra $203 \mathrm{~cm}$ desse intervalo sedimentar os tipos polínicos arbóreos (Cecropia), herbáceos (Poaceae), hidrófitas (Cyperaceae), os esporos de Pteridophyta e Pseudoschizae, sendo que somente Cecropia apresentou alta nos valores de concentração em relação a amostra anteriormente analisada (Figuras 2 e 3).

A fina camada de areia-lamosa (amostra 200/201 cm) que se inseriu entre as argilas se mostrou estéril em palinomorfos (Figuras 2 e 3). Após isso, novamente as argilas se depositaram, e os valores observados em relação à concentração total na amostra 193/194 cm continuaram a declinar em relação à base do testemunho de sondagem (cerca de 10.000 palinomorfos/grama de sedimento) (Figuras 2 e 3). Os tipos arbóreos apareceram pela primeira vez (Inga). Na categoria arbóreos somente Cecropia foi observada, na dos arbustivos somente Piper, ambas com baixas concentrações. Prevaleceram na amostra as hidrófitas (Cyperaceae e Typhaceae ) e os esporos de Pteridophyta. Somente Poaceae foi observada nos herbáceos e na categoria hábito variável somente Amaranthus, Cleome e Sapindaceae. Nenhuma alga foi observada nessa amostra (Figura 3). O estado de preservação dos palinomorfos dessa amostra se mostrou bastante prejudicado principalmente pelos altos percentuais 


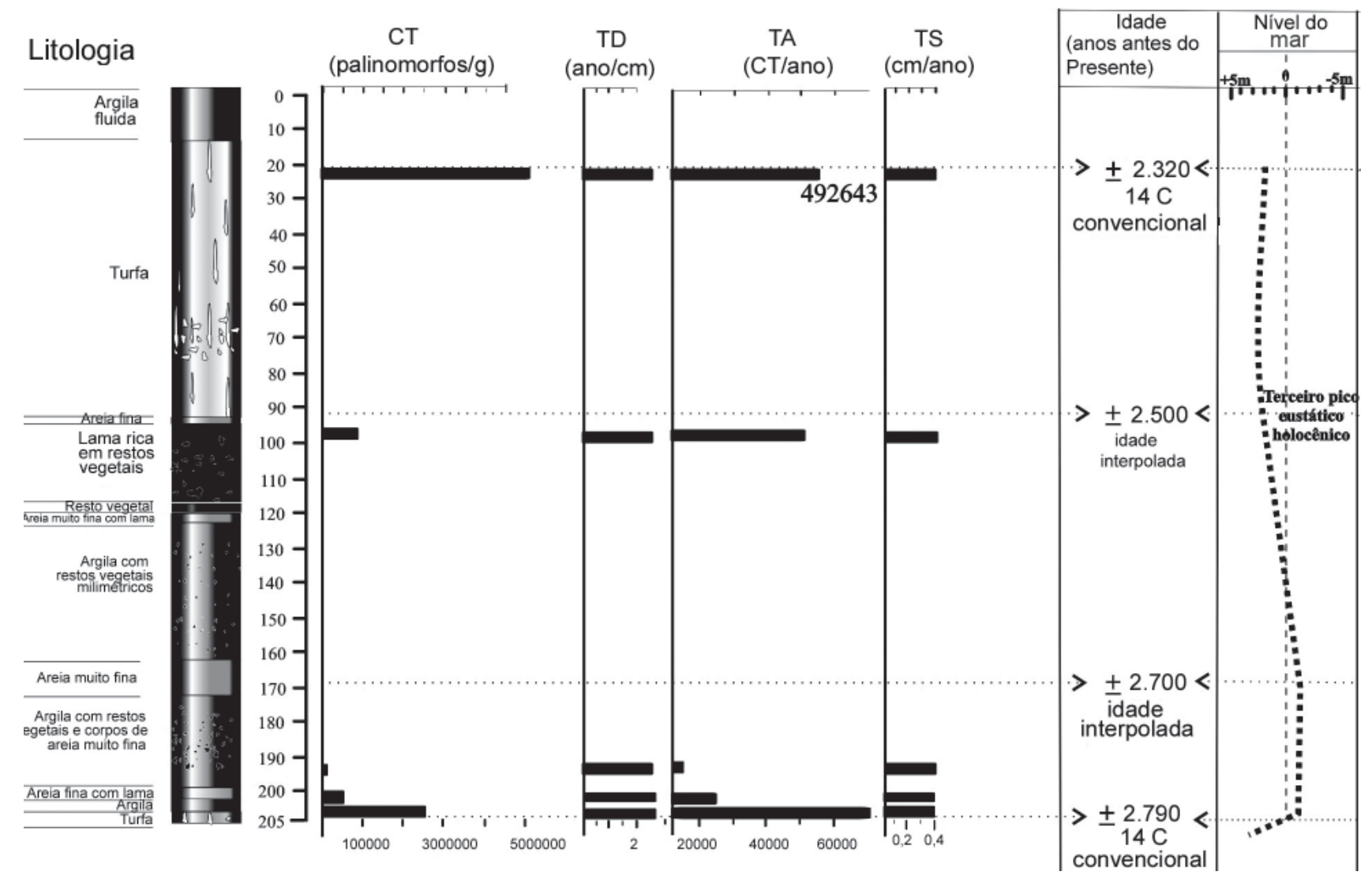

Figura 2. Litologia do testemunho de sondagem Campelo 2001. Abreviaturas: CT, concentração total dos palinomorfos (palinomorfos/ g); TD, tempo de deposição (ano/cm); TA, taxa de acumulação total dos palinomorfos (CT/ano); TS, taxa de sedimentação (cm/ano). Datações radiocarbônicas convencionais e idades interpoladas x curva do nível do mar, segundo Martin et al. (1997).

Figure 2. Litology of the core Campelo 2001. Abbreviations: TC, total concentration of palynomorphs (palynomorphs/g); TD, deposition time (year/cm); TA; total accumulation rate of palynomorphs (CT/year); TS, sedimentation rate (cm/year). Conventional radiocarbon dating and interpolated ages $x$ sea level according to Martin et al. (1997).

de grãos de pólen e esporos com danos mecânicos (22\%) e corroídos $(14 \%)$, somente apresentando diminuição os percentuais dos degradados $(3 \%)$ em relação às amostras anteriormente analisadas.

$\mathrm{Na}$ amostra $98 / 99 \mathrm{~cm}$, localizada no intervalo lamoso do testemunho de sondagem, a concentração total dos palinomorfos apresentou alta em relação à amostra anterior (cerca de 100.000 palinomorfos/grama de sedimento) (Figuras 2 e 3). Os tipos arbóreos aumentaram suas concentrações devido aos primeiros registros de Celtis e Trema. Os tipos arbóreos/arbustivos em conjunto prevaleceram na amostra (Alchornea, Cecropia e Myrtaceae). Na categoria arbustivos, Piper apresentou valores mais elevados em comparação com a amostra anterior e foi o primeiro registro de Struthanthus no testemunho. No entanto, prevaleceram na amostra Cecropia, Borreria, Poaceae, Moraceae, Typha e Pteridophyta que apresentaram aumento nas concentrações em relação à última amostra analisada. Os esporos de Bryophyta ressurgiram nas contagens, com concentrações menores do que na base do testemunho de sondagem. Em relação às algas, foram observados pela primeira vez no testemunho de sondagem os zigósporos de Mougeotia. O percentual dos palinomorfos com a exina degradada voltou a crescer (22\%), caindo os corroídos (1\%) e os com danos mecânicos (10\%).
Já na camada turfosa mais próxima do topo do testemunho de sondagem $(20 / 21 \mathrm{~cm})$ se deu o predomínio dos herbáceos (Borreria e Poaceae). Essa amostra demonstrou maior riqueza e alta concentração total de palinomorfos (cerca de 500.000 palinomorfos/grama de sedimento) (Figuras 2 e 3). As hidrófitas voltaram a crescer em valores, principalmente Cyperaceae. Dentre as algas Botryococcus, Cosmarium, Pseudoschizaea e Spyrogira foram observadas, com predomínio da primeira. Dentre os arbóreos, Meliaceae e Trema foram observados. Dentre os arbóreos/arbustivos, predominaram Cecropia, Clethra Myrsinaceae e Tabebuia. Nos arbustivos, somente Piper foi observado. Pela primeira vez foram observadas Lianas (Serjania). Também pela primeira vez foram observados herbáceos/arbustivos (Cuphea e Ichthyothere/Aspilia). Amaranthus, Asteraceae, Cleome, Euphorbiaceae, Melastomataceae/Combretaceae, Moraceae, Ochnaceae, Rhamanaceae e Rubiaceae foram observados para a categoria de hábito variável. O estado de preservação das exinas apresentou melhora em relação à última amostra analisada, sendo baixo o percentual de grãos de pólen e esporos corroídos $(0,5 \%)$ e com danos mecânicos $(9 \%)$, se bem que o percentual dos degradados continuou alto $(16 \%)$. 


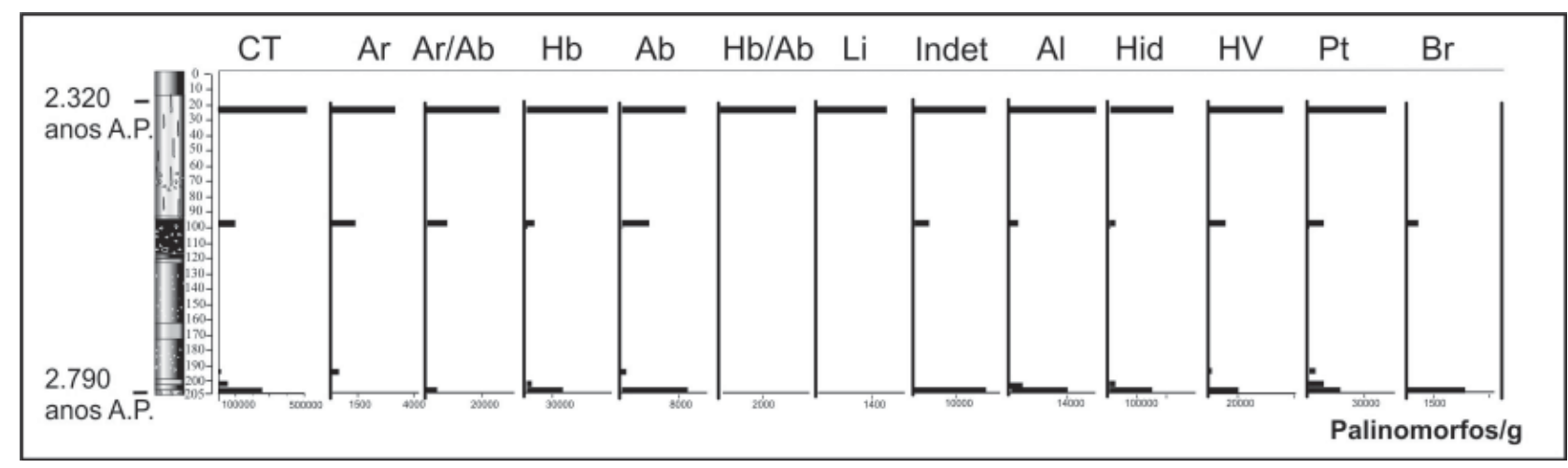

Figura 3. Litologia do testemunho de sondagem e concentrações totais dos tipos polínicos por hábito das plantas. Abreviaturas: CT, concentração total; Ar, arbóreo; Ab, arbustivo; Hb, herbáceo; Li, lianas; Indet, indeterminados; Al, algas; Hid, hidrófitas; HV, hábito variável; Pt, Pteridophyta; $\mathbf{B r}$, Bryophyta.

Figure 3. Lithology of the core and total pollen concentrations related to the plant habitus. Abbreviations: $\mathbf{C T}$, total concentration; Ar, trees; Ab, shrubs; Hb, herbs; Li, lianas; Indet, indeterminates; Al, algae; Hid, hidrophyte; Pt, Pteridophyta; Br, Bryophyta.

\section{DISCUSSÃO}

A análise do testemunho da lagoa do Campelo evidenciou que há cerca de 2.800 anos A. P. o nível do mar estava mais baixo do que o atual, como dito para vários locais do Brasil por Martin et al. (1993). No local de estudo desenvolveu-se uma turfeira, com uma baixa lâmina de água. Possivelmente, isso se deu devido a progradação da desembocadura do rio Paraíba do Sul, que descarregava suas águas a jusante. A vegetação desta turfeira era composta principalmente por Poaceae, Cyperaceae, Selaginella, Pteridophyta, Bryophyta, Cabomba, Polygonum, Sagittaria, Scrophulariaceae, Typhaceae, Araceae e Borreria. Uma alta concentração de Pseudoschizae e um grande percentual de palinomorfos que apresentaram a exina degradada e corroída corroboram esse fato, no período. A mata do entorno foi refletida por tipos higrófilos e pioneiros na sucessão vegetal (Alchornea, Cecropia, Loranthaceae e Piper). Plantas das famílias Asteraceae, Euphorbiaceae, Melastomataceae/ Combretaceae, Moraceae, Ochnaceae, Rhamnaceae e Tiliaceae podiam estar tanto nesta mata quanto colonizando outros tipos de vegetação em áreas mais abertas. A produção de grãos de pólen e esporos nesse período foi grande, muito em função dos herbáceos e das hidrófitas da própria turfeira, o que ocasionou uma alta taxa de acumulação total (cerca de 70.000 palinomorfos/grama de sedimento/ano).

Após esse ocorrido, o nível de base desceu ainda mais por, pelo menos, 100 anos. Acumulou-se no local, durante esse período, ora argilas, ora areias, como possível conseqüência de flutuações na vazão do rio Paraíba do Sul. A amostra 203/204 cm retirada da argila basal mostrou uma grande queda na taxa de acumulação total (cerca de 30.000 palinomorfos/grama de sedimento/ano), uma baixa riqueza dos tipos polínicos no geral e uma baixa concentração daqueles relativos à mata. Já na argila rica em restos vegetais (amostra 193/194 cm), um alto percentual de corroídos foi visto, indicando provavelmente exposição dos palinomorfos ao ar atmosférico e aos ataques microbianos, típicos de ambientes mais secos. Provavelmente, o local de deposição preferencial dos palinomorfos se dava ainda à jusante, por causa da permanência do mar regressivo. Durante esse evento, no local depositaram-se, preferencialmente, os esporos de Pteridophyta, o pólen de Poaceae, Cyperaceae e tipos polínicos de uma mata higrófila pioneira.

Após 2.700 anos A. P., o nível do mar gradualmente subiu até que, em 2.500 anos A. P., houve o terceiro pico positivo holocênico e a erosão na desembocadura do rio Paraíba do Sul (Martin et al., 1993). Estes fatos podem ter facilitado o aumento no nível de água da lagoa. A amostra analisada desse período $(98 / 99 \mathrm{~cm})$ apresentou deposição de lamas ricas em restos vegetais e cuja taxa de acumulação total apresentou valores mais altos em relação às encontradas nas argilas basais (cerca de 55.000 palinomorfos/grama de sedimento/ ano). A riqueza dos tipos polínicos da mata aumentou (Alchornea, Cecropia, Celtis, Trema, Piper, Struthanthus, Myrtaceae), mas ainda refletia uma mata pioneira e higrófila. O pólen de hidrófitas e os esporos de Pteridophyta foram observados em menor concentração em relação às amostras anteriores. Observou-se, pela primeira vez, zigósporos de Mougeotia como indicadores de água doce. Foi alta a contribuição dos herbáceos, principalmente de Borreria. O percentual de degradados foi alto, indicando entrada na lagoa de pólen e esporos expostos ao ar atmosférico. Toledo et al. (1994, 1995) e Toledo (1998) realizaram análises palinológicas nos sedimentos da lagoa Salgada, localizada próximo à foz do rio Paraíba do Sul, em sua margem direita, obtendo uma idade aproximada de 2.540 anos A.P. (idade convencional $\left.{ }^{14} \mathrm{C}\right)$. Segundo estes autores, ocorreu um evento de proporções regionais que causou uma alteração no curso deste rio, formando, ao norte de sua desembocadura, uma laguna costeira. Esta mudança teria provocado uma seca no ambiente da lagoa Salgada, com a ocorrência de lâminações carbonáticas e alta deposição de Amaranthus/ Chenopodiaceae, Poaceae e Asteraceae, assim como uma acentuada redução nas concentrações dos esporos de Pteridophyta e Bryophyta. Na área da lagoa do Campelo, por volta de 2.500 anos A.P., foi visto que a sedimentação lamosa deu entrada a uma pequena camada de areia de granulometria fina e após isso o desenvolvimento de uma turfeira que permaneceu por pelo menos 200 anos no local. De acordo 
com Martin et al. (1993), o nível do mar na costa do Brasil se manteve alto até pelo menos 2.300 anos A. P. e a lagoa do Campelo, nesse período, apresentou a maior taxa de acumulação de palinomorfos de todo o testemunho de sondagem (492.643 palinomorfos/grama de sedimento/ano). Isso se deu, principalmente, pelo aumento nos esporos de Pteridophyta, nos tipos polínicos herbáceos (Poaceae e Borreria) e herbáceos/arbustivos (Cuphea, Ichthyotherel Aspilia), nas hidrófitas (Typha, Polygonum, Scrophulariaceae e Cyperaceae) e nas algas (Cosmarium e Spyrogira). A presença nessa amostra de algas de água doce e de percentuais menores de degradados e corroídos indicam alta no nível de água da lagoa. A mata paludosa se mostrou mais rica (Clethra, Myrsinaceae, Tabebuia, Meliaceae Cecropia, Piper, Serjania e Trema), mas ainda em estágio pioneiro.

O registro sedimentar posterior a 2.320 anos A.P foi quase nulo. Este fato pode ser relacionado com as dragagens que retiraram os sedimentos de fundo da lagoa para construção dos canais do Vigário e Antônio Rezende. A abertura deste último canal pode ter provocado o carreamento de parte dos sedimentos do leito da lagoa para jusante, em direção ao mar. Os problemas ambientais ocasionados por estas mudanças hidráulicas na lagoa do Campelo podem estar relacionados ao aumento expressivo na sedimentação das algas nas amostras do sedimento de superfície como visto em Luz (2003). Este estudo evidenciou que na atualidade a maior deposição dos grãos de pólen relaciona-se a Typha e cuja área de maior concentração relacionou-se à borda nordeste da lagoa. A borda sudoeste apresentou altas porcentagens de grãos de pólen e esporos com a exina degradada e com danos mecânicos, sendo a de menor concentração de grãos de pólen. A energia eólica associada com a batimetria - que propicia a colonização de determinadas plantas em bancos de areia expostos - são os fatores mais importantes na deposição diferencial atual de palinomorfos na superfície de fundo da lagoa do Campelo. Esta não apresenta tributários, e áreas protegidas e mais profundas são facilitadoras na deposição e preservação dos palinomorfos. A turbulência causada pelo vento na margem sudoeste provoca aí uma menor concentração de palinomorfos, pois estes provavelmente sofrem constantes ressuspensões. Os palinomorfos ressuspendidos são transportados pelas correntes geradas e misturados com os sedimentos originados em diferentes partes da bacia, podendo ser estes originários de diferentes estratos deposicionais. Suas exinas demonstram claramente os processos de destruição que os palinomorfos sofrem durante o transporte e a fossildiagênese numa lagoa costeira rasa. De acordo com Koff et al. (2000), a fonte predominante de grãos de pólen em um lago de tamanho pequeno é a vegetação presente em torno de $200 \mathrm{~m}$. Os grãos de pólen e os esporos sedimentados previamente nos solos desta área freqüentemente são expostos à oxidação e à atividade microbiana. As sucessivas secas e inundações causam danos significativos a estes grãos de pólen e esporos e esses danos são rápidos e severos (Campbell, 1991). Provavelmente, ocorre uma sedimentação prévia e temporária de grãos de pólen e esporos em áreas brejosas adjacentes à lagoa do Campelo e sujeitas a secas temporárias. Durante as chuvas, estes grãos de pólen e esporos são arrastados e introduzidos pela orla da lagoa. As plantas herbáceas locais da lagoa dominaram a assembléia polínica na atualidade (Cyperaceae, Poaceae e Typhaceae), assim como os produtores de esporos (Pteridophyta e Bryophyta). Vários tipos polínicos arbóreos/arbustivos identificados nas amostras de superfície são representativos da Floresta Estacional Semidecidual (Casearia, Combretaceae, Cupania, Dorstenia, Euphorbiaceae, Fabaceae, Gochnatia, Lecythidaceae, Meliaceae, Moraceae, Piper, Rapanea, Rubiaceae, Sapotaceae, Sloanea, Solanaceae, Trichilia, Trema e Virola) e alguns deles apresentaram elevadas concentrações como Alchornea, Arecaceae, Cecropia, Celtis, Clethra e Myrtaceae. De acordo com o estudo de Silva \& Nascimento (2001), as famílias Myrtaceae e Leguminosae foram as de maior riqueza em espécies na "Mata do Carvão", mata remanescente deste tipo florestal localizado próximo à área de estudo. Os tipos polínicos representativos da vegetação de restinga e observados nas amostras de superfície por Luz (2003) foram Alchornea, Arecaceae, Casearia, Cupania, Gochnatia, Loranthaceae, Meliaceae, Myrtaceae, Rapanea, Sloanea e Trichilia, estando de acordo com o estudo de Assumpção \& Nascimento (2000) nas restingas localizadas em área próxima à lagoa do Campelo. Em relação à vegetação arbórea apontada por Luz (2003) como higrófila, os tipos polínicos Alchornea, Arecaceae, Casearia, Cecropia, Celtis, Cupania, Moraceae, Myrcia, Piper, Rapanea, Sloanea, Trema, Trichilia e Virola podem ter como área-fonte um pequeno remanescente de mata localizado em sua margem nordeste, já que o transporte polínico de longa distância deve ser consideravelmente reduzido nesta lagoa, devido ao seu tamanho. As amostras de superfície apresentaram altos valores de concentração em algas (Pediastrum tetras foi a espécie dominante, sendo também observadas zigósporos de Spirogyra e Mougeotia ). Quando se comparam estes resultados com os do testemunho de sondagem, observa-se que a representatividade da floresta apresentou menor riqueza em tipos polínicos no testemunho (26 tipos polínicos que podem ser relacionados à floresta contra 40 tipos polínicos arbóreos e arbóreos/arbustivos observados nas amostras da superfície). O espectro polínico refletido no testemunho de sondagem foi de uma mata higrófila pioneira, enquanto o da superfície apresentou tipos polínicos de plantas mais bem estabelecidas na sucessão ecológica. Este fato pode estar relacionado às instabilidades ambientais ocorridas em relação ao nível de base durante os 500 anos analisados e que dificultaram o assentamento da floresta no entorno da lagoa do Campelo, neste período.

A influência antrópica não foi diretamente refletida nos espectros palinológicos do testemunho de sondagem, como a presença de tipos polínicos de plantas cultivadas ou evidências do uso do fogo, mas o grande aumento na concentração de zigósporos e coenobium de algas em conjunto com a de hidrófitas nas amostras do sedimento de superfície visto por Luz (2003) pode estar relacionado à grande perda de água que a lagoa do Campelo vêm sofrendo. 


\section{AGRADECIMENTOS}

A Luciane G. Coelho pela colaboração no Tilia Graph, ao Conselho Nacional de Desenvolvimento Científico e Tecnológico e à Fundação de Amparo à Pesquisa do Rio de Janeiro pelo apoio financeiro, incluindo a concessão de bolsa à primeira autora.

\section{REFERÊNCIAS}

Angely, J. 1959. Dicionário de Botânica. Curitiba, Instituto Paranaense de Botânica, 407 p.

Araújo, D.S.D. \& Henriques, R.P.B. 1984. Análise florística das restingas do Estado do Rio de Janeiro. In: RESTINGAS: ORIGEM, ESTRUTURA E PROCESSOS. Resumos expandidos, Niterói, UFF, p. 159-193.

Assumpção, J. \& Nascimento, M.T. 2000. Estrutura e composição florística de quatro formações vegetais de restinga no complexo lagunar Grussaí/Iquipari, São João da Barra, Rio de Janeiro, Brasil. Acta Botânica Brasílica, 14(3):301-315.

Bidegain, P. 2002. Lagoas do Norte Fluminense - perfil ambiental. Rio de Janeiro, Fundação Superintendência de Rios e Lagoas (SERLA), 148 p. (Boletim 14).

Bove, C.P.; Gil, A.S.B.; Moreira, C.B. \& Anjos, R.F.B. 2003. Hidrófitas fanerogâmicas de ecossistemas aquáticos temporários da planície costeira do Estado do Rio de Janeiro, Brasil. Acta Botânica Brasílica, 17(1):119-135.

Campbell, I.D. 1991. Experimental mechanical destruction of pollen grains. Palynology, 15:29-33.

Carauta, J.P.P.; Lima, D.F.; Vianna, M.C.; Ascenção, M.R. \& Lins, E.A.M. 1992. Vegetação da floresta da Cicuta, Estado do Rio de Janeiro, observações preliminares. Albertoa, 11(3):101-124.

Carauta, J.P.P. \& Rocha, E.S.F. 1988. Conservação da flora do trecho fluminense da bacia hidrográfica do rio Paraíba do Sul. Albertoa, 11(1):86-135.

Carauta, J.P.P.; Vianna, M.C.; Araújo, D.S.D. \& Oliveira, R.F. 1978. A vegetação de "Poço das Antas". Bradea, 46(2):299-305.

Esteves, F.A.; Ishii, I. \& Camargo, A.F. 1984. Pesquisas limnológicas em 14 lagoas do litoral do Estado do Rio de Janeiro. In: RESTINGAS: ORIGEM, ESTRUTURA, PROCESSOS, 1984. Resumos expandidos, Niterói, UFF, p. 443-454.

FAB/DRM. 1976. Mapa fotográfico aéreo da lagoa do Campelo, Estado do Rio de Janeiro, Brasil, escala 1:20.000.

FEEMA- Fundação Estadual de Engenharia do Meio Ambiente. 1993. Perfil ambiental do município de Campos. Rio de Janeiro, $146 \mathrm{p}$.

Grimm, E.C. 1987. Coniss: a 77 program for stratigraphically constrained cluster analysis by the method of incremental sum of squares. Computer \& Geosciences, 2:13-35.

Guedes-Bruni, R.R.; Pessoa, S.V.A. \& Kurtz, B.C. 1997. Florística e estrutura do componente arbustivo-arbóreo de um trecho preservado de floresta montana na Reserva Ecológica de Macaé de Cima. In: H.C. Lima \& R. R. Guedes-Bruni (eds.) Serra de Macaé de Cima: diversidade florística e conservação em Mata Atlântica, Jardim Botânico do Rio de Janeiro, p. 127-145.

IBGE. 1968. Mapa topográfico de Campos de Goitacazes, Estado do Rio de Janeiro, Brasil, escala 1:50.000.

Jacobson, G.L. \& Bradshaw, R.H.W. 1981. The selection of sites for paleovegetational studies. Quaternary Research, 16:80-96.

Koff, T.; Punning, J. \& Kangur, M. 2000. Impact of forest disturbance on the pollen influx in lake sediments during the last century. Review of Palaebotany and Palynology, 111:19-29.
Kurtz, B.C. \& Araújo, D.S.D. 2000. Composição florística e estrutura do componente arbóreo de um trecho de Mata Atlântica na Estação Ecológica Estadual do Paraíso, Cachoeiras de Macacu, RJ, Brasil. Rodriguésia, 51(78/79):69-111.

Lima, H.C.; Nascimento, M.T. \& Silva, G.C. 1998. Aspectos florísticos e importância conservacionista de um remanescente florestal no norte fluminense. In: CONGRESSO NACIONAL DE BOTÂNICA, 49, 1998, Boletim de Resumos, Salvador, p. 409.

Luz, C.F.P. 2003. Os registros palinológicos como sensores das dinâmicas da vegetação no Holoceno da região norte do estado do Rio de Janeiro (Brasil). Programa de Pós-graduação em Geologia, Universidade Federal do Rio de Janeiro, Tese de Doutorado, 168 p.

Martin, L.; Bittencourt, A.C.S.P.; Flexor, J.M. \& Vilas-Boas, G.S. 1984. Enregistrement de pèriodes de fortes et faibles ènergies à l'embouchure d'un fleuve: le cas du Paraíba do Sul (Brèsil). Implications palèoclimatiques. Comptes rendus Hebdomadaires des Seances de l'academie des Siences, ser. 2, 299:661-664.

Martin, L.; Dominguez, J.M.L.; Suguio, K.; Flexor, J.M. 1997. Geologia do Quaternário costeiro do litoral norte do Rio de Janeiro e do Espírito Santo. CPRM - Serviço Geológico do Brasil, 112 p.Martin, L.; Suguio, K. \& Flexor, J.M. 1993. As flutuações de nível do mar durante o Quaternário Superior e a evolução geológica de "deltas" brasileiros. Boletim IG- USP, Publicação Especial 15, 186 p.

Moreno, M.R.; Nascimento, M.T. \& Kurtz, B.C. 1998. Estrutura e composição florística do estrato arbóreo em duas zonas altitudinais diferentes em Mata Atlântica de encosta na região do Imbé, RJ: Primeira aproximação. In: SIMPÓSIO DE ECOSSISTEMAS BRASILEIROS, 4, 1998. Resumos expandidos, Águas de Lindoia, ACIESP, p. 64-70.

Moreno, M.R.; Nascimento, M.T. \& Kurtz, B.C. 2003. Estrutura e composição florística do estrato arbóreo em duas zonas altitudinais na Mata Atlântica de encosta na região do Imbé, RJ. Acta Botânica Brasílica, 17(3):371-386.

Pessoa, S.V.A.; Guedes-Bruni, R.R. \& Kurtz, B.C. 1997. Composição florística e estrutura do componente arbustivo-arbóreo de um trecho secundário de floresta montana na Reserva Ecológica de Macaé de Cima. In: H.C. Lima \& R.R. Guedes-Bruni (eds.) Serra de Macaé de Cima: diversidade florística e conservação em Mata Atlântica, Jardim Botânico do Rio de Janeiro, p. 147-167.

RADAMBRASIL. 1983. Levantamento de recursos naturais, Geologia, Geomorfologia, Pedologia, Vegetação. Uso Potencial da Terra (Folhas SF 23/24-RJ -Vitória), Brasília, Ministério das Minas e Energia, v. 32, 78 p.

Reid, J. \& Esteves, F.A. 1984. Considerações ecológicas e biogeográficas sobre a fauna de copépodes (Crustaceae) planctônicos e bentônicos de 14 lagoas costeiras do Estado do Rio de Janeiro, Brasil. In: RESTINGAS: ORIGEM, ESTRUTURA E PROCESSOS, 1984. Resumos expandidos, Niterói, UFF, p. 305-326.

Scheel-Ybert, R. 2000. Vegetation stability in the Southeastern Brazilian coastal area from 5500 to $140014 \mathrm{C}$ yr BP deduced from charcoal analysis. Review of Palaeobotany \& Palynology, 110:111-138.

Silva, G.C. \& Nascimento, M.T. 2001. Fitossociologia de um remanescente de mata sobre tabuleiros do norte do Estado do Rio de janeiro (mata do Carvão). Revista Brasileira de Botânica, 24(1):51-62. 
Soffiati Neto, A.A. 1985. A agonia das lagoas do Norte Fluminense. Ciência e Cultura, 37(10):1627-1638.

Soffiati Neto, A.A. 1997. Destruição e proteção da Mata Atlântica no Rio de Janeiro: ensaio bibliográfico acerca da eco-história. História, Ciências, Saúde - Manguinhos, 4(2). Disponível em http://www.coc.fiocruz.br/hscience/index_port.htm (acesso em 20/07/2004).

Stockmar, J. 1971. Tablets spores used in absolute pollen analysis. Pollen et Spores, 13(4):615-621.

Toledo, M.B. 1998. Evolução ambiental da lagoa Salgada, sudeste do Brasil, com base em estudos palinológicos. Programa de Pós-graduação em Geologia Marinha, Universidade Federal Fluminense, Dissertação de Mestrado, 40 p.

Toledo, M.B.; Barros, M.A. \& Barth, O.M. 1994. Contribuição à palinologia da lagoa Salgada, Rio de Janeiro. In: REUNIÃO DE PALEOBOTÂNICOS E PALINÓLOGOS, 8, 1994. Boletim de Resumos, São Paulo, USP, p. 81.
Toledo, M.B.; Barros, M.A.; Barth, O.M.; Lemos, R.M. \& Silva, C.G. 1995. Contribuição à palinologia da lagoa Salgada, Rio de Janeiro. In: CONGRESSO DAASSOCIAÇÃO BRASILEIRA DE ESTUDOS DO QUATERNÁRIO, 5, 1995. Boletim de Resumos, Niterói, UFF, p. 22-27.

Veloso, H.P.; Rangel Filho, L.R. \& Lima, J.C.A. 1991. Classificação da vegetação brasileira adaptada a um sistema universal. Rio de Janeiro, Publicação Instituto Brasileiro de Geografia, 124 p.

Ybert, J.P.; Salgado-Labouriau, M.L.; Barth, O.M.; Lorscheitter, M.L.; Barros, M.A.; Chaves, S.A.M.; Luz, C.F.P.; Ribeiro, M.B.; Scheel, R. \& Vicentini, K.F. 1992. Sugestões para padronização da metodologia empregada em estudos palinológicos do Quaternário. Boletim do Instituto Geológico, 13:47-49.

Received January, 2006; accepted March, 2006

Apêndice 1. Tipos polínicos observados no testemunho Campelo 2001. Abreviaturas: TPTB, Tipos polínicos de táxons botânicos identificados; FOD, Floresta Ombrófila Densa; FES, Floresta Estacional Semidecidual; R, Restinga; C, Campos; P, Palustres; H, Hidrófitas. Appendix 1. Observed pollen types in the core Campelo 2001. Abbreviations: TPTB, Pollen types of identified botanical taxa; FOD, Ombrofilous Forest; FES, Seasonal Semideciduous Forest; R, Restinga; C, Fields; P, Marsh vegetation; H, Hydrophytes.

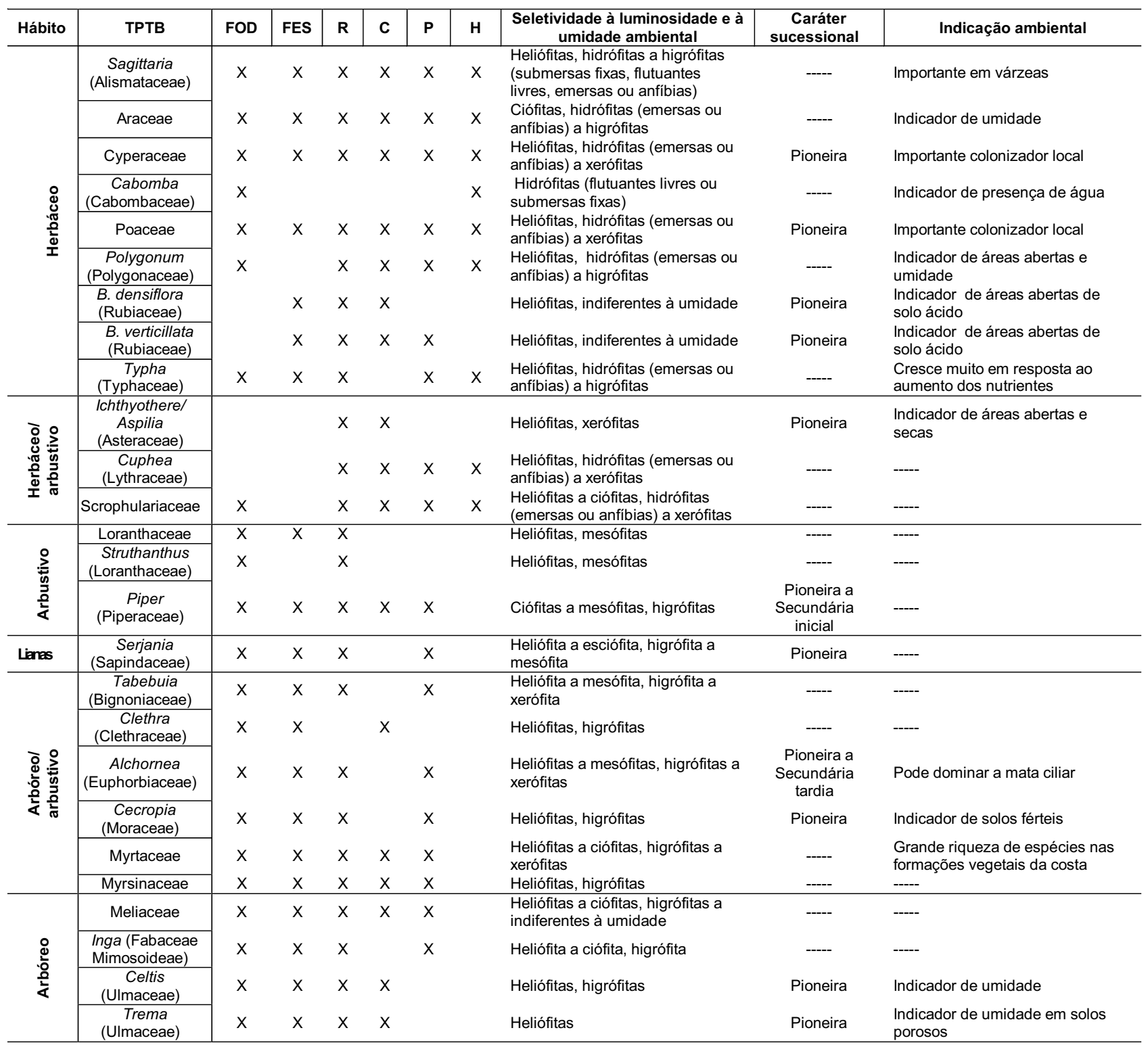


Apêndice 1. Continuação

Appendix 1. Continued

\begin{tabular}{|c|c|c|c|c|c|c|c|c|c|c|}
\hline Hábito & TPTB & FOD & FES & $\mathbf{R}$ & C & $\mathbf{P}$ & $\mathbf{H}$ & $\begin{array}{c}\text { Seletividade à luminosidade e } \\
\text { umidade ambiental }\end{array}$ & $\begin{array}{c}\text { Caráter } \\
\text { sucessional }\end{array}$ & Indicação ambiental \\
\hline \multirow{16}{*}{$\begin{array}{l}\bar{\Phi} \\
\substack{\frac{\pi}{2} \\
\frac{\pi}{\pi}}\end{array}$} & \begin{tabular}{|c|} 
Amaranthus \\
Amaranthaceae \\
\end{tabular} & $\mathrm{x}$ & $X$ & & $x$ & \multirow{3}{*}{$\mathrm{X}$} & \multirow{3}{*}{$\mathrm{x}$} & Heliófitas, higrófitas a xerófitas & ---- & \multirow[t]{2}{*}{$\begin{array}{l}\text { Indicador de áreas } \\
\text { abertas }\end{array}$} \\
\hline & Asteraceae & $\mathrm{x}$ & $\mathrm{X}$ & $x$ & $x$ & & & $\begin{array}{l}\text { Heliófita a ciófita, hidrófitas } \\
\text { (emersas ou anfíbias) a xerófitas }\end{array}$ & $\begin{array}{l}\text { Pioneira a } \\
\text { Secundária } \\
\text { inicial }\end{array}$ & \\
\hline & $\begin{array}{c}\text { Cleome } \\
\text { (Capparidaceae) } \\
\end{array}$ & $\mathrm{x}$ & $\mathrm{X}$ & $x$ & $x$ & & & $\begin{array}{l}\text { Heliófitas a ciófitas, higrófitas a } \\
\text { xerófitas }\end{array}$ & ---- & ----- \\
\hline & Euphorbiaceae & $x$ & $\mathrm{X}$ & $x$ & $x$ & $x$ & $\mathrm{X}$ & $\begin{array}{l}\text { Heliófitas a mesófitas, hidrófitas } \\
\text { (emersas ou anfíbias) a } \\
\text { indiferentes à umidade }\end{array}$ & $\begin{array}{l}\text { Pioneira a } \\
\text { Secundária } \\
\quad \text { tardia }\end{array}$ & Importante em várzeas \\
\hline & $\begin{array}{c}\text { Melastomataceae } \\
\text { Combretaceae }\end{array}$ & $x$ & $x$ & $x$ & $x$ & $x$ & $x$ & $\begin{array}{l}\text { Heliófitas a indiferentes, hidrófitas } \\
\text { (emersas ou anfíbias) a xerófitas }\end{array}$ & $\begin{array}{l}\text { Pioneira a } \\
\text { Secundária } \\
\text { inicial }\end{array}$ & ---- \\
\hline & $\begin{array}{c}\text { Acácia } \\
\text { (Fabaceae) } \\
\text { Mimosoideae) }\end{array}$ & $\mathrm{x}$ & $x$ & $x$ & & & & $\begin{array}{l}\text { Heliófitas a mesófitas, higrófitas a } \\
\text { xerófitas }\end{array}$ & Pioneira & ---- \\
\hline & Monocotyledonea & $\mathrm{x}$ & $\mathrm{X}$ & $x$ & $x$ & $x$ & $\mathrm{X}$ & $\begin{array}{l}\text { Heliófitas a ciófitas, hidrófitas } \\
\text { (emersas ou anfíbias) a xerófitas }\end{array}$ & ----- & ---- \\
\hline & Moraceae & $x$ & $x$ & $x$ & $x$ & $x$ & & $\begin{array}{l}\text { Heliófitas a ciófitas, higrófitas a } \\
\text { indiferentes à umidade }\end{array}$ & Pioneira & $\begin{array}{l}\text { Indica solos férteis. } \\
\text { Importante em áreas de } \\
\text { distúrbio e várzeas }\end{array}$ \\
\hline & Ochnaceae & $\mathrm{x}$ & $\mathrm{X}$ & $x$ & $x$ & $x$ & $x$ & $\begin{array}{l}\text { Heliófitas, hidrófitas (emersas ou } \\
\text { anfíbias) a xerófitas }\end{array}$ & $\begin{array}{l}\text { Secundária } \\
\text { inicial }\end{array}$ & ----- \\
\hline & Oxalidaceae & $\mathrm{x}$ & $\mathrm{X}$ & $x$ & $x$ & & & $\begin{array}{l}\text { Heliófitas a esciófitas, higrófitas a } \\
\text { xerófitas }\end{array}$ & ---- & ----- \\
\hline & Rhamnaceae & $x$ & $x$ & $x$ & $x$ & & & Heliófitas a ciófitas, higrófitas & ---- & ---- \\
\hline & Rubiaceae & $\mathrm{x}$ & $\mathrm{X}$ & $x$ & $x$ & $x$ & $\mathrm{X}$ & $\begin{array}{l}\text { Heliófitas a ciófitas, hidrófitas } \\
\text { (emersas ou anfíbias) a xerófitas }\end{array}$ & $\begin{array}{c}\text { Secundária } \\
\text { inicial e tardia }\end{array}$ & -- \\
\hline & Sapindaceae & $\mathrm{x}$ & $\mathrm{X}$ & $x$ & $\mathrm{x}$ & $x$ & & $\begin{array}{l}\text { Heliófitas a mesófitas, higrófitas a } \\
\text { mesófitas }\end{array}$ & $\begin{array}{l}\text { Pioneira e } \\
\text { Secundária } \\
\text { inicial }\end{array}$ & Importante em várzeas \\
\hline & Solanaceae & $\mathrm{x}$ & $\mathrm{X}$ & $x$ & $\mathrm{x}$ & & & $\begin{array}{l}\text { Heliófitas a ciófitas, higrófitas a } \\
\text { xerófitas }\end{array}$ & $\begin{array}{l}\text { Pioneira a } \\
\text { Secundária } \\
\text { tardia }\end{array}$ & $\begin{array}{l}\text { Importante em áreas de } \\
\text { distúrbio e várzeas }\end{array}$ \\
\hline & Tiliaceae & $x$ & $\mathrm{x}$ & $x$ & $x$ & $x$ & $x$ & $\begin{array}{l}\text { Heliófitas, hidrófitas (emersas ou } \\
\text { anfíbias) a xerófitas }\end{array}$ & $\begin{array}{l}\text { Secundária } \\
\text { tardia }\end{array}$ & ----- \\
\hline & Verbenaceae & $\mathrm{x}$ & $x$ & $x$ & $\mathrm{x}$ & & & Heliófitas, higrófitas a xerófitas & $\begin{array}{l}\text { Pioneira a } \\
\text { Secundária } \\
\text { tardia }\end{array}$ & ----- \\
\hline
\end{tabular}

